\title{
Physiological responses to salinity increases in the freshwater silversides Odontesthes bonariensis and O. hatcheri (Pisces, Atherinidae)
}

\author{
Mônica Y. Tsuzuki ${ }^{1}$; Hideki Aikawa ${ }^{2}$; Carlos A. Strüssmann ${ }^{1}$ \& Fumio Takashima ${ }^{1}$ \\ ${ }^{1}$ Tokyo University of Fisheries, Department of Aquatic Biosciences \\ (4-5-7 Konan, Minato-ku, Tokyo 108-8477, Japan) \\ e-mail: monica_tsuzuki@hotmail.com \\ ${ }^{2}$ Inland Water Experimental Station, Kanagawa Prefecture Fisheries Research Center \\ (Ooshima 3657, Sagamihara-shi, Kanagawa-ken 229-1135, Japan)
}

- Descriptors: Salinity tolerance, Cortisol, Osmoregulation, Stress, Pejerrey, Atherinidae.

- Descritores: Tolerância a salinidade, Cortisol, Osmoregulação, Estresse, Peixe-rei, Atherinidae.

\section{Introduction}

Members of the family Atherinidae display various degrees of salinity tolerance and as a result they have radiated into a wide range of environments (Hubbs et al., 1971; Bamber \& Henderson, 1988; Middaugh et al., 1990). The pejerrey or silverside, Odontesthes bonariensis (Valenciennes, 1835), is an important commercial species native to temperate and sub-tropical inland waters of South America. Pejerrey has been introduced into several countries, including Japan, as a game fish or as a candidate for freshwater aquaculture (Bonetto \& Castello, 1985). The congeneric $O$. hatcheri (formerly Patagonina hatcheri; Dyer, 1993), from freshwaters of Patagonia, Argentina, is also a potential species for cultivation in temperate areas (Strüssmann et al., 1997).

Although these species are commonly propagated in freshwater, preliminary evidence gathered in seed production centers and commercial fish farms in Japan suggests that moderate salinities allow better performance, in particular the attainment of stable survival rates under stress conditions (Murayama et al., 1977; Umezawa \& Nomura, 1984; Strüssmann et al., 1996; Tsuzuki et al., 2000b). Studies with larvae and juveniles of both species also showed best survival and growth rates at intermediate salinities, although the optimum salinity for each species varied considerably (Tsuzuki, 1999; Tsuzuki et al., 2000a).

The present study had the dual purpose of comparing the salinity tolerance of sub-adults of $O$. bonariensis and $O$. hatcheri, and obtaining preliminary information on their osmoregulatory and compensatory stress responses under different $\mathrm{NaCl}$ concentrations. Sodium chloride instead of seawater was used in this study because these are the salts most commonly employed to raise salinity during husbandry practices of these species. Thus, there was also an interest in the elucidation of the relation between $\mathrm{NaCl}$ and improved performance. The study consisted of the analysis of survival and blood parameters $\mathrm{CNa}^{+}$and $\mathrm{Cl}^{-}$ion levels, osmolality, hematocrit and cortisol) in fish gradually or directly exposed to salinities between 0 and $3.0 \% \mathrm{NaCl}$.

\section{Materials and methods}

The experiment was conducted with hatchery-reared sub-adults of Odontesthes bonariensis (mean body weight of $24.1 \mathrm{~g}$ and total length of $16.1 \mathrm{~cm})$ and $O$. hatcheri $(27.8 \mathrm{~g}$ and 18.1 $\mathrm{cm})$ at the Inland Water Experimental Station, Kanagawa Prefecture Fisheries Research Center, Japan. Fish raised in freshwater were transferred to 200-liter tanks and allowed to acclimate to the tanks in running water $(0 \% \mathrm{NaCl})$ for 10 days before experimentation at a density of $150 \mathrm{fish} / \mathrm{m}^{3}$. During this period, fish were not disturbed except for feeding, which consisted of the administration of commercial pellets (EX ayu \#3; Nihon Nousan Kougyou Ltd.) twice daily to satiation. No food was distributed $24 \mathrm{~h}$ prior to and during the experimental period. Temperature was kept at $19 \pm 1{ }^{\circ} \mathrm{C}$ and aeration was provided to maintain dissolved oxygen near saturation levels. Natural photoperiod conditions were used in the experiment. No mortality occurred during the acclimation period.

In order to measure the osmotic and normal compensatory stress responses, salinity in the test 
tanks was abruptly changed to $0,0.5,1.0,2.0$ and 3.0 $\% \mathrm{NaCl}$, or gradually increased to $1.0,2.0$ and $3.0 \%$ $\mathrm{NaCl}$ (increases of $0.5 \% \mathrm{NaCl}$ per day), by addition of a concentrated stock solution of $\mathrm{NaCl}$. The stock solution was prepared by dissolution of commercial grade $\mathrm{NaCl}$ salt in fresh water. Salinity was measured with an optical refractometer (Atago) to the nearest $0.1 \%$.

Blood samples were collected from 4-5 fish from each salinity group immediately before, and at $3,9,24$ and $168 \mathrm{~h}$ after the salinity increase (or the attainment of the final salinity levels in gradually acclimated groups). For this purpose, fish were quickly anesthetized $\left(0.5 \mathrm{ml} . \mathrm{l}^{-\mathrm{I}^{-}} 2\right.$ phenoxyethanol $)$, the size of the fish was recorded, and blood was drawn from caudal vessels into lithium-heparinized syringes. Hematocrit was measured immediately with an autocrit centrifuge (Clay Adams Ltd:; 11,500 rpm, 10 minutes). Plasma was separated from the whole blood by centrifugation at $3,000 \mathrm{rpm}$ for $10 \mathrm{~min}$, and stored at $-85^{\circ} \mathrm{C}$ until analysis. The following analysis were made: plasma cortisol, with the $\mathrm{I}^{125}$ radioimmunoassay cortisol kit (SPAC-S Cortisol Kit, Japan), osmolality, with a vapor pressure osmometer (Wescor Inc.), $\mathrm{Cl}^{-}$and $\mathrm{Na}^{+}$, with an ion meter (Shimadzu CIM-104A). Because pejerrey of the size employed in this study have little blood (only 0.3-0.4 $\mathrm{ml}$ can be taken from one individual), it was necessary to pool the blood from all fish in each sampling to obtain sufficient volume for analysis. Due to this limitation, individual variations could not be assessed. However, because samples were pooled, each value supposedly approximates the true mean of 4-5 individuals. Survival rates were calculated from the number of surviving fish between each sampling period.

\section{Results and discussion}

The gradual acclimation to salinity in daily increments of $0.5 \% \mathrm{NaCl}$ did not effect any changes in the results of survival, osmoregulatory and stress responses in comparison to the corresponding groups subjected to direct transfer. For this reason, data for gradually acclimated groups are not presented in the figures. No mortality occurred at salinities between 0 and $2.0 \% \mathrm{NaCl}$ for both species (results not shown). In contrast, mortality rates reached $100 \%$ within $3 \mathrm{~h}$ in $O$. hatcheri and within $24 \mathrm{~h}$ in $O$. bonariensis after transfer to $3.0 \% \mathrm{NaCl}$. Thus, the upper limit for the survival of sub-adults of these species falls between 2.0 and $3.0 \% \mathrm{NaCl}$. Although the present study dealt with different concentrations of $\mathrm{NaCl}$ instead of seawater, the results suggest a tolerance to a wide range of salinities. This might indicate that sub-adults of both species are also euryhaline, as has been observed with eggs, larvae and juveniles (Tsuzuki, 1999; Tsuzuki et al., 2000a).
Conspicuous changes in plasma $\mathrm{Na}^{+}, \mathrm{Cl}^{-}$and osmolality occurred only at 2.0 and $3.0 \% \mathrm{NaCl}$ in both species, where all three parameters increased, and at $0 \% \mathrm{NaCl}$ in $O$. bonariensis, where $\mathrm{Cl}^{-}$levels were somewhat lower than at other salinities (Fig. 1). Decreases and increases in plasma $\mathrm{Cl}^{-}$also occurred during recovery after stress at 0 and $3.0 \% \mathrm{NaCl}$, respectively, in sub-adults of striped bass Morone saxatilis (Cech et al., 1996). Higher plasma osmolality, $\mathrm{Na}^{+}$or $\mathrm{Cl}^{-}$with increasing water salinity was also observed in other species when individuals were exposed to different dilutions of seawater (Morgan \& Iwama, 1991; Altinok et al., 1998; Vonck et al., 1998). In our study, Odontesthes bonariensis seemed to osmoregulate more efficiently than $O$. hatcheri at $2.0 \% \mathrm{NaCl}$ as total osmolality, $\mathrm{Na}^{+}$and $\mathrm{Cl}^{-}$returned to basal levels within 1 week in the former but not in the latter species.

Hematocrit values varied widely, particularly in $O$. hatcheri, precluding an accurate comparison between salinities and species. However, values seemed to be lower in $O$. bonariensis than in $O$. hatcheri and to vary grossly in inverse proportion to salinity in both species (Fig. 1). The lowest values were obtained in animals at $3.0 \% \mathrm{NaCl}$ just before $100 \%$ mortality. A similar trend of decreased hematocrit value with increasing salinity was observed in chinook salmon Oncorhynchus tshawytscha fry (Morgan \& Iwama, 1991) and in sturgeon Acipenser oxyrinchus de sotoi (Altinok et $a l ., 1998$ ) when animals were transferred from diluted to full-strength seawater. On the other hand, the opposite phenomenon occurred in rainbow trout $O$. mykiss (Morgan \& Iwama, op. cit.). Morgan \& Iwama (1991) attributed these variable responses to speciesspecific differences in red blood cell and plasma volume changes.

Plasma cortisol also varied markedly but values were somewhat lower and more stable at 2.0 and $1,0 \% \mathrm{NaCl}$ in 0 . bonariensis and $O$. hatcheri, respectively, compared to other salinities (Fig. 1). Lower cortisol levels might suggest either a natural preference for these particular salinity levels, resulting in decreased cortisol secretion, or an increase in the metabolic clearance rate of cortisol, as observed by Nichols \& Weisbart (1985) after transfer of Atlantic salmon Salmo salar to seawater. It is interesting to note that animals kept at $0 \%$ salinity, originally considered the natural condition for both species, did not present the lowest cortisol levels. In fact, the lowest levels found for both species at $0 \%$ salinity in this and subsequent studies (Tsuzuki, 1999 Tsuzuki et al. 2000b) are 7- to 10-fold higher than the basal levels reported for stenohaline freshwater species such as carp Cyprinus carpio (Abo Hegab \& Hanke, 1984) and goldfish Carassius auratus (Barton \& Iwama, 1991). In comparison to euryhaline species reared in fresh water, the resting levels for pejerrey 

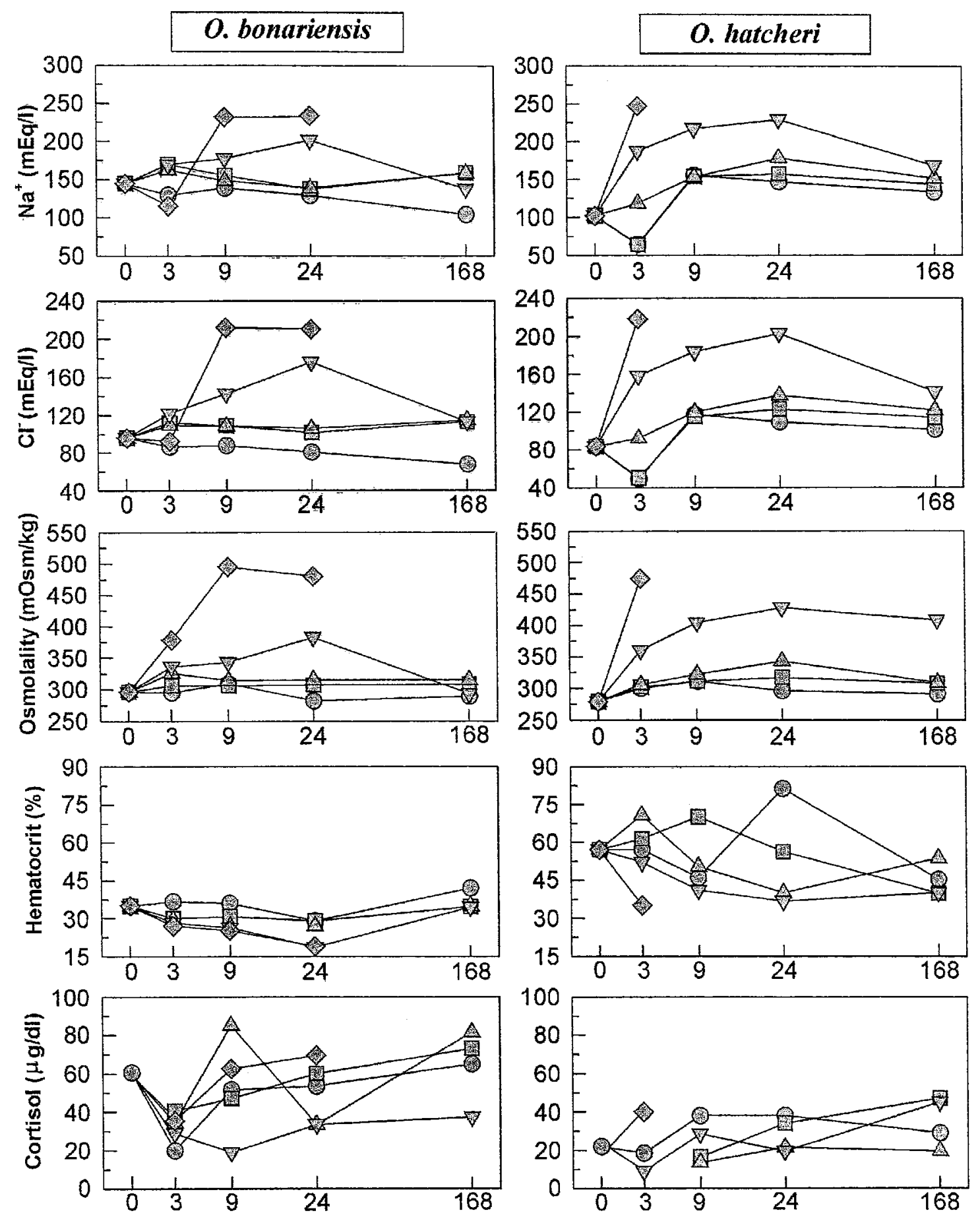

Time (h)

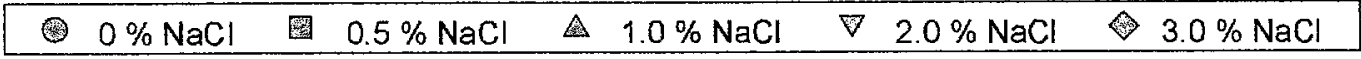

Fig. 1. Plasma $\mathrm{Na}^{+}, \mathrm{Cl}^{-}$and osmolality, hematocrit and plasma cortisol in sub-adults of Odontesthes bonariensis and $O$. hatcheri during exposure to salinities of $0-3.0 \% \mathrm{NaCl}$. Cortisol values for $O$. bonariensis at $3 \mathrm{~h}$ for 0.5 and $1.0 \% \mathrm{NaCl}$ could not be included due to problems during analysis. 
were 10- to 20-fold higher than those for tilapia Oreochromis mossambicus (Assem \& Hanke, 1981; Abo Hegab \& Hanke, 1984), and 4- to 5-fold higher than those for the striped bass Morone saxatilis (Barton \& Iwama, 1991; Cech et al., 1996). The former is a freshwater species whereas the latter is an estuarine species. The physiological and ecological significance of these levels of cortisol for pejerrey is still unknown. However, since cortisol increases during stress and since it promotes water influx across the gills with subsequent loss of electrolytes (e.g. $\left.\mathrm{Cl}^{-}\right)$ in fresh water (Mazeaud \& Mazeaud, 1981; Wedemeyer et al., 1990), high cortisol levels could precipitate and/or potentiate osmoregulatory dysfunction at $0 \%$ salinity. Likewise, fresh water made difficult to maintain stable ion levels during or after stress in brown trout Salmo trutta (Nikinmaa et al., 1983), walleye Stizostedion vitreum (Barton \& Zitzow, 1995) and striped bass Morone saxatilis (Cech et. al., 1996).

The results of cortisol and $\mathrm{Cl}^{-}$ion obtained in the present study could be an indication that $O$. bonariensis and $O$. hatcheri are not truly adapted to 0 $\%$ salinity. This hypothesis is supported by evidence that the family Atherinidae, which is considered primarily a marine coastal group, only recently invaded freshwater environments (Bamber \& Henderson, 1988). In fact, many species of the genus Odontesthes that are regarded as freshwater species can be found in brackish waters such as in estuaries and lagoons (Martty, 1992), suggesting that the transition of these species to freshwater environments is still not completed. On the other hand, these observations are consistent with the lack of differences in salinity tolerance between sub-adults transferred gradually or abruptly to different salinities in this study, as well as in larvae and juveniles as reported by Tsuzuki (1999) and Tsuzuki et al. (2000a). This lack of difference seems to be coherent with a natural ability of these species to cope with short-term, abrupt variations in salinity that can be expected in estuarine environments (Bamber \& Henderson, 1988).

The above findings suggest that the subadults of both species respond similarly at intermediate salinities but not at extreme ones. Thus, Odontesthes bonariensis seems to tolerate high salinities better than $O$. hatcheri, whereas the reverse occurs in low salinities. The results also raise a question on the adequacy of freshwater, especially during situations of stress, for the rearing of both species and point to a possible effect of salinity on plasma cortisol levels. Ongoing research should help clarify the points raised in this study and elucidate the physiological roles of salts in the promotion of survival and in the reduction of stress-induced osmotic and ionic imbalances.

\section{Acknowledgements}

We thank the staff of the Inland Water Fisheries Experimental Station, Kanagawa Prefecture Fisheries Research Center, for support and for providing the materials and access to facilities for this study. We also thank Dr. Jiro Koyama and Dr. Masashi Maita for assistance with ion and cortisol measurements. We appreciated the technical help of Chiho Shirakusa and Masami Hashimoto. During this research the senior author was supported by allowances from the Ministry of Education, Science, Sports and Culture of Japan (Monbusho) and Fapesp (Fundação de Amparo à Pesquisa do Estado de São Paulo).

\section{References}

Abo Hegab, S. A. \& Hanke, W. 1984. The significance of cortisol for osmoregulation in carp (Cyprinus carpio) and tilapia (Sarotherodon mossambicus). Gen. Comp. Endocrinol., 54(3):409-417.

Altinok, I.; Galli, S. M. \& Chapman, F. A. 1998. Ionic and osmotic regulation capabilities of juvenile Gulf of Mexico sturgeon, Acipenser oxyrinchus de sotoi. Comp. Biochem. Physiol., 120A(4):609-616.

Assem, H. \& Hanke, W. 1981. Cortisol and osmotic adjustment of the euryhaline teleost, Sarotherodon mossambicus. Gen. Comp. Endocrinol., 43(3):370-380.

Bamber, R. N. \& Henderson, P. A. 1988. Preadaptive plasticity in atherinids and the estuarine seat of teleost evolution. J. Fish Biol., 33:17-23.

Barton, B. A. \& Iwama, G. K. 1991. Physiological changes in fish from stress in aquaculture with emphasis on the response and effects of corticosteroids. Annu. Rev. Fish Dis., 1:3-26.

Barton, B. A. \& Zitzow, R. E. 1995. Physiological responses of juvenile walleyes to handling stress with recovery in saline water. Prog. Fish-Cult., 57:267-276.

Bonetto, A. A. \& Castello, H. B. 1985. Pesca y piscicultura en aguas continentales de America Latina. Washington, OEA. $118 \mathrm{p}$.

Cech Jr., J. J.; Bartholow, S. D.; Young, P. S. \& Hopkins, T. E. 1996. Striped bass exercise and handling stress in freshwater: physiologica! responses to recovery environment. Trans. Am. Fish. Soc., 125(2):308-320. 
Dyer, B. S. 1993. A phylogenetic study of atheriniform fishes with a systematic revision of the South American silversides (Atherinomorpha, Atherinopsinae, Sorgentinini). Tese de doutorado. University of Michigan. 596p.

Hubbs, C.; Sharp, H. B. \& Schneider, J. F. 1971. Developmental rates of Menidia audens with notes on salt tolerance. Trans. Am. Fish. Soc., 100(4):603-610.

Martty, H. 1992. Manual del pejerrey (nomenclaturareproducción-pesca). Buenos Aires, Albatroz. $159 \mathrm{p}$.

Mazeaud, M. M. \& Mazeaud, F. 1981. Adrenergic responses to stress in fish. In: Pickering, A. D., ed. Stress and fish. London, Academic Press. p.49-75.

Middaugh, D. P.; Hemmer, M. J.; Shenker, J. M. \& Takita, T. 1990. Laboratory culture of jacksmelt, Atherinopsis californiensis, and topsmelt, Atherinopsis affinis (Pisces: Atherinidae), with a description of larvae. Calif. Fish Game, 76(1):413.

Morgan, J. D. \& Iwama, G. K. 1991. Effects of salinity on growth, metabolism, and ion regulation in juvenile rainbow and steelhead trout (Oncorhynchus myskiss) and fall chinook salmon (Oncorhynchus tshawytscha). Can. J. Fish. Aquat. Sci., 48:2083-2094.

Murayama, T.; Nishihara, A. T.; Ishizaki, H. \& Oyama, S. 1977. High density rearing of pejerrey $O$. bonariensis in brackishwater. Rep. Kanagawa Pref. Freshwat. Fish Prop. Exper. Station, 13:2226.

Nichols, D. J. \& Weisbart, M. 1985. Cortisol dynamics during seawater adaptation of Atlantic salmon, Salmo salar. Am. J. Phys., 248(6):R651R659.

Nikinmaa, M.; Soivio, A.; Nakari, T. \& Lindgren, S. 1983. Hauling stress in brown trout (Salmo trutta): physiological responses to transport in fresh water or salt water, and recovery in natural brackish water. Aquaculture, 34(1-2):93-99.

Strüssmann, C. A.; Moriyama, S.; Hanke, E. F.; Calsina Cota, J. C. \& Takashima, F. 1996. Evidence of thermolabile sex determination in pejerrey. J. Fish Biol., 48(4):643-651.
Strüssmann, C. A.; Akaba, T.; Ijima, K.; Yamaguchi, K.; Yoshizaki, G. \& Takashima, F. 1997. Spontaneous hybridization in the laboratory and genetic markers for the identification of hybrids between two atherinid species, Odontesthes bonariensis (Valenciennes 1835) and Patagonina hatcheri (Eigenmann 1909). Aquac. Res., 28(4):291-300.

Tsuzuki, M. Y. 1999. Effects of salinity on viability, physiology and stress induced responses in the pejerrey Odontesthes bonariensis and $O$. hatcheri. Tese de doutorado. Tokyo, Tokyo University of Fisheries. 85p.

Tsuzuki, M. Y.; Aikawa, H.; Strüssmann, C. A. \& Takashima, F. 2000a. Comparative survival and growth of embryos, larvae, and juveniles of pejerrey Odontesthes bonariensis and $\mathrm{O}$. hatcheri at different salinities. J. Appl. Ichthyol., 16(3):126-130.

Tsuzuki, M. Y. Ogawa, K.; Strüssmann, C. A.; Maita, M. \& Takashima, F. 2000b. Physiological responses during stress and subsequent recovery at different salinities in adult pejerrey Odontesthes bonariensis. Aquaculture (in press).

Umezawa, K. \& Nomura, H. 1984. Transportation of pejerrey Odontesthes bonariensis. Rep. Saitama Pref. Freshwat. Fish Prop. Exper. Station, 43:8286.

Vonck, A. P. M. A.; Bonga, S. E. W. \& Flik, G. 1998. Sodium and calcium balance in mozambique tilapia, Oreochromis mossambicus, raised at different salinities. Comp. Biochem. Physiol., 119A (2):441-449.

Wedemeyer, G. A.; Barton, B. A. \& McLeay, D. J. 1990. Stress and acclimation. In: Schreck, C. B. \& Moyle, P. B., eds. Methods for fish biology. Bethesda, American Fisheries Society. p. 451489.

(Manuscript received 29 July 1999; revised 24 April 2000; accepted 29 June 2000) 